Supplementary information to:

\title{
High DMS and monoterpene emitting big leaf Mahogany trees: discovery of a missing DMS source to the atmospheric environment
}

Lejish Vettikkat ${ }^{1}$, Vinayak Sinha ${ }^{1}$, Savita Datta ${ }^{1}$, Ashish Kumar ${ }^{1}$, Haseeb Hakkim ${ }^{1,}$ and Priya Yadav $^{1}$, 5 Baerbel Sinha ${ }^{1}$

${ }^{1}$ Department of Earth and Environmental Sciences, Indian Institute of Science Education and Research Mohali, Sector 81, S. A. S. Nagar, Manauli PO, Punjab, 140306, India

Correspondence to: Dr. Vinayak Sinha (vsinha@iisermohali.ac.in) 


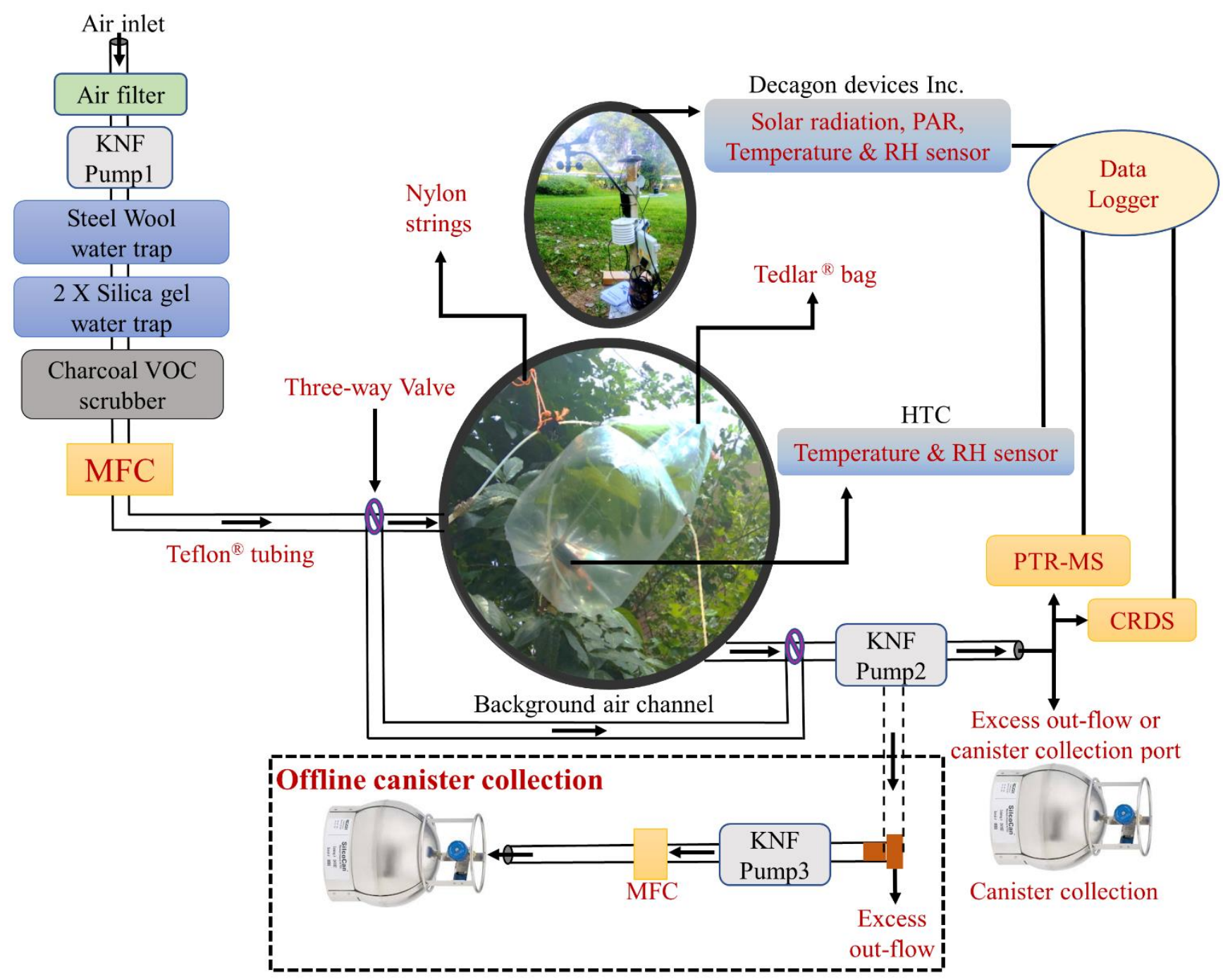

Figure S1. Schematic of dynamic branch cuvette setup. Offline canister collection scheme is depicted in the dashed rectangle. MFC: Mass flow controller.PTR-MS: proton transfer reaction mass spectrometry.CRDS: Cavity ring down spectroscopy.PAR: Photosynthetically active radiation. 


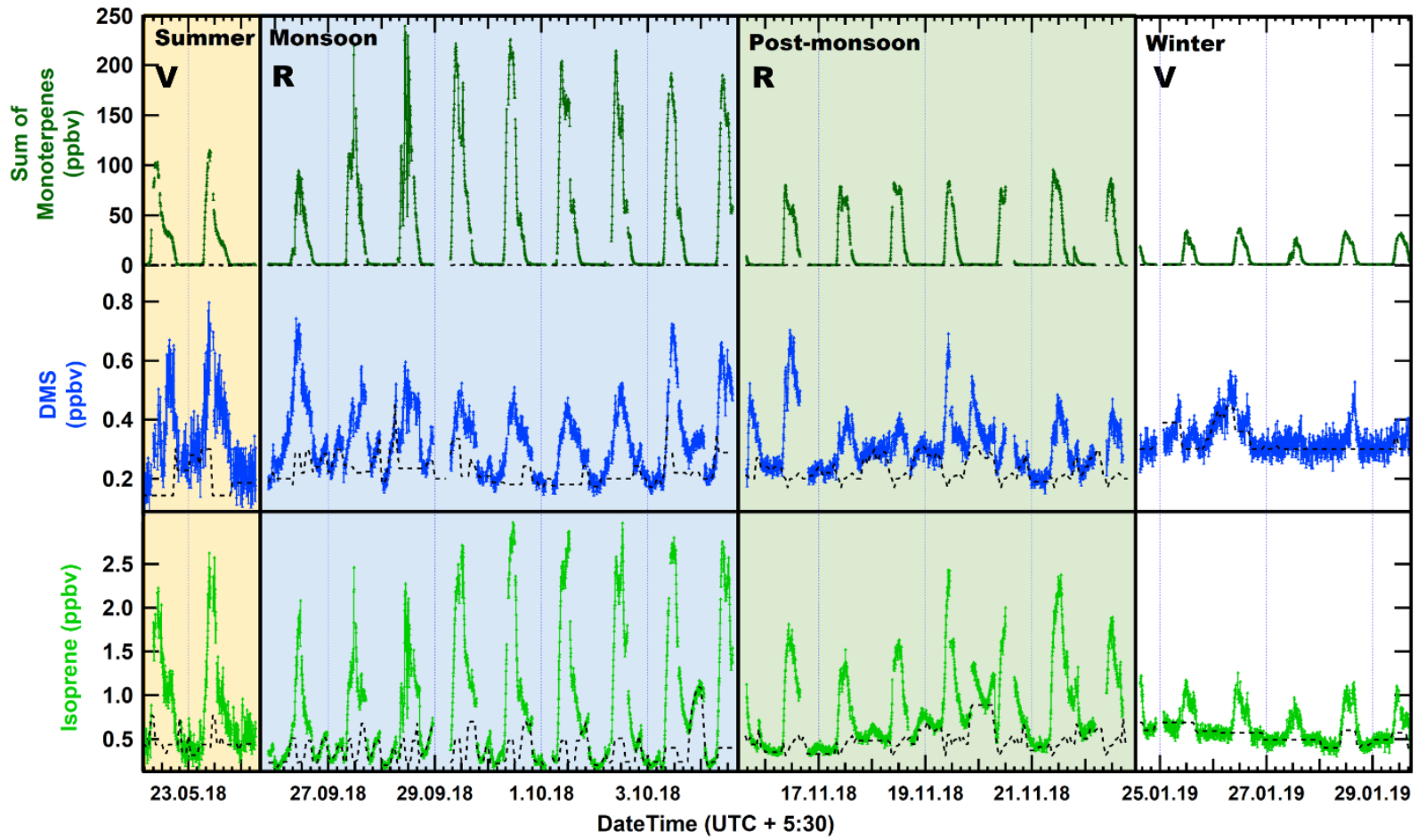

Figure S2: Time series of BVOC emissions with the corresponding background concentrations in nmol mol ${ }^{-1}$ Background concentrations are shown as dotted line. 


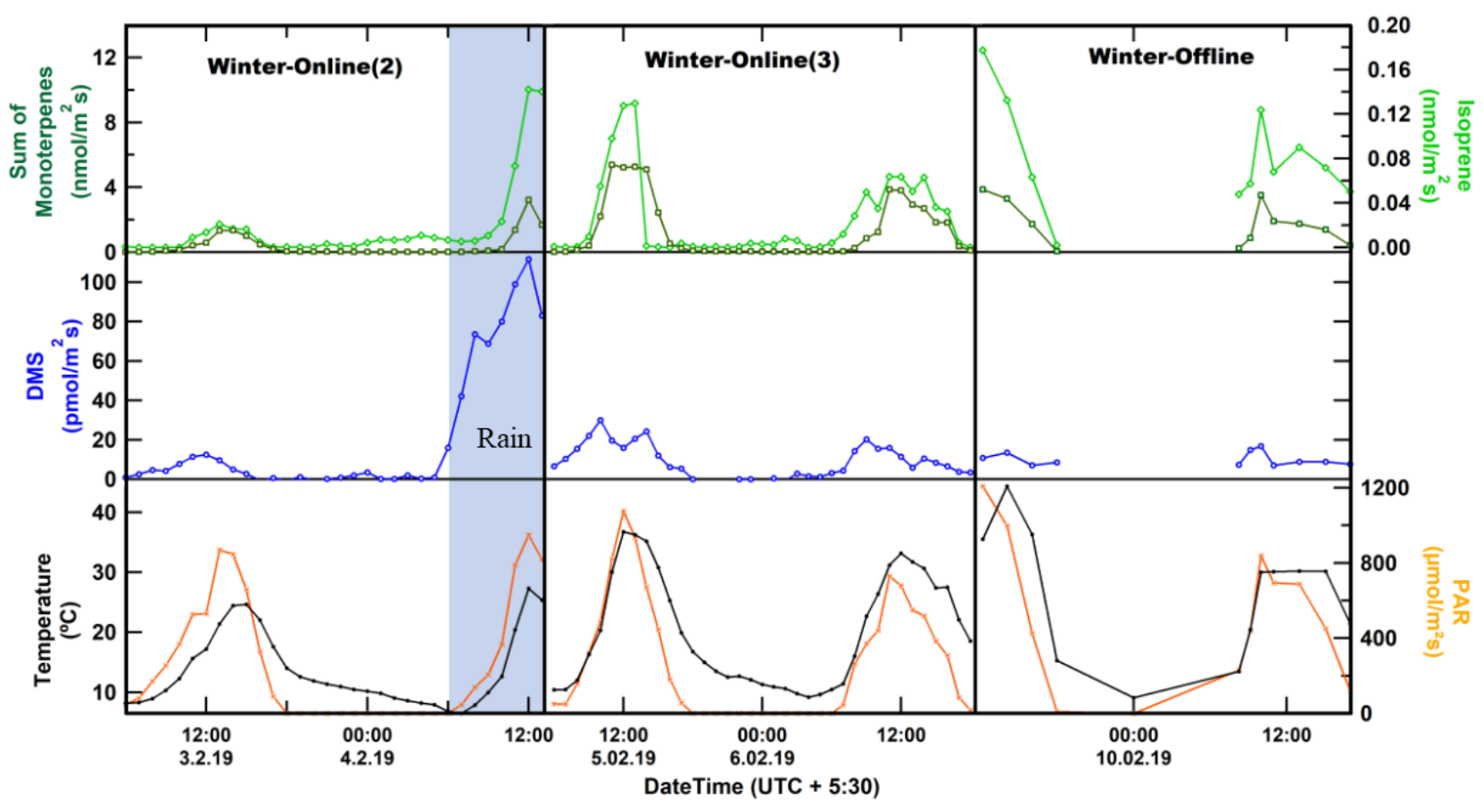

Figure S3: Wintertime BVOC fluxes along with PAR and temperature. (expressed in nanomols or picomols per leaf area per second). Blue shaded region shows rainy period. 


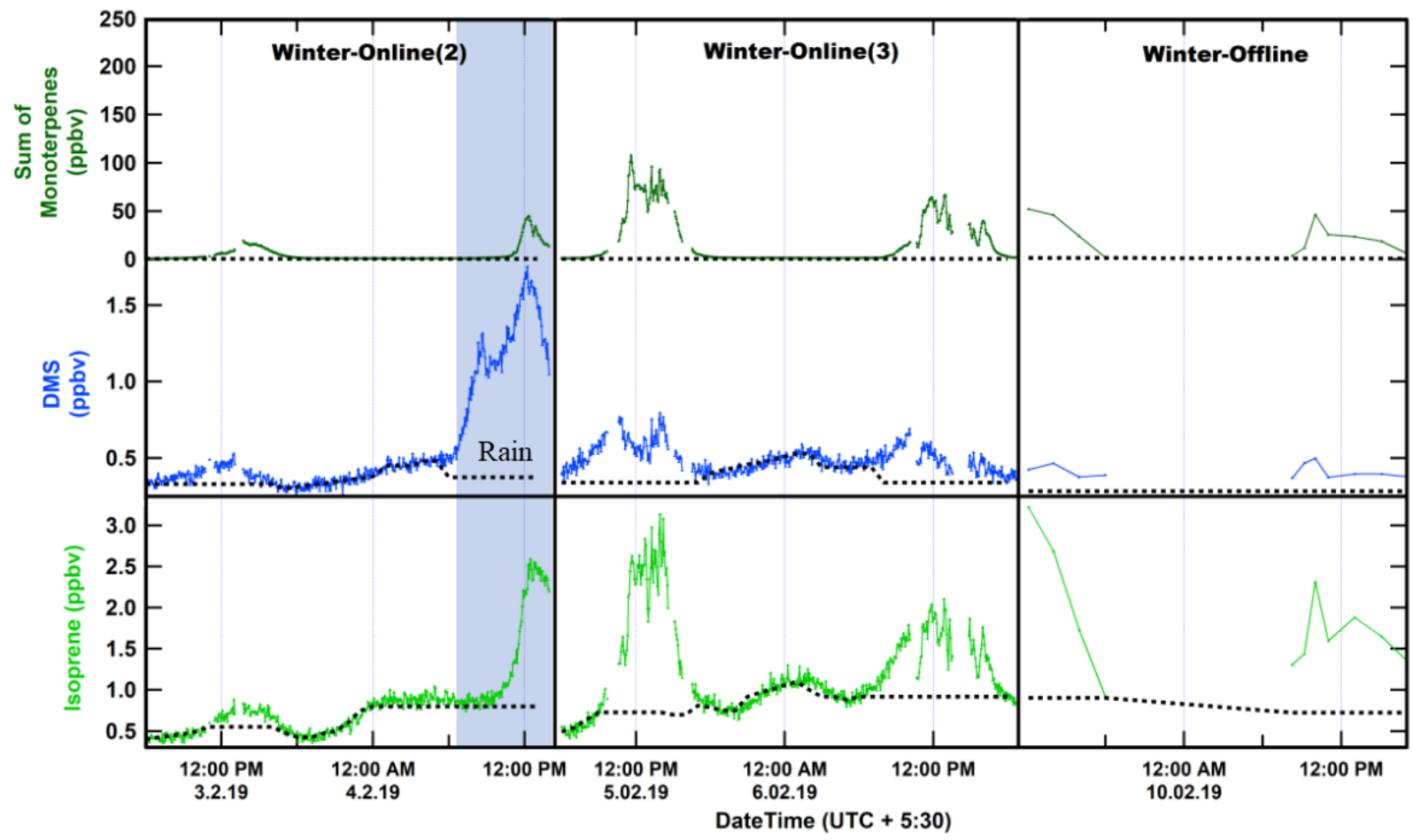

Figure S4: Time series of Wintertime BVOC emissions with the corresponding background concentrations in nmol mol $^{-1}$ Background concentrations are shown as dotted line. Blue shaded region shows rainy period. 
Table S1. Leaf area and leaf dry weight inside the cuvette during all the experiments

\begin{tabular}{lccc}
\hline Season & Leaf area $\left(\mathbf{m}^{\mathbf{2}}\right)$ & Leaf dry weight $(\mathbf{g})$ & $\mathbf{g} / \mathbf{m}^{2}$ \\
\hline Summer & 0.3 & 30.1 & 96.1 \\
Monsoon & 0.3 & 28.2 & 82.8 \\
Post-monsoon & 0.2 & 20.5 & 109.4 \\
Winter & 0.2 & 26.8 & 135.3 \\
Winter (2) & 0.3 & 27.3 & 102.3 \\
Winter (3) & 0.2 & 31.7 & 138.9 \\
Winter-Offline & 0.3 & 36.1 & 139.8 \\
\hline
\end{tabular}

